University of Warwick institutional repository: http://go.warwick.ac.uk/wrap This paper is made available online in accordance with publisher policies. Please scroll down to view the document itself. Please refer to the repository record for this item and our policy information available from the repository home page for further information.

To see the final version of this paper please visit the publisher's website. Access to the published version may require a subscription.

Author(s): FABIENNE PETER and HANS BERNHARD SCHMID Article Title: SYMPOSIUM ON RATIONALITY AND COMMITMENT: INTRODUCTION

Year of publication: 2005

Link to published version:

http://dx.doi.org/10.1017/S0266267104000343

Publisher statement: None 


\section{SYMPOSIUM ON RATIONALITY AND COMMITMENT: INTRODUCTION}

Fabienne Peter

University of Warwick

Hans Bernhard Schmid

University of St. Gallen

In Rational Fools, Amartya Sen (1977) put forward a piercing critique of rational choice theory. The argument hinges on the distinction between three types of motivation - (narrow) self-interest, sympathy, and commitment. One acts from self-interest when one aims at maximizing one's welfare, where welfare is understood as depending exclusively on the goods enjoyed by oneself. Sympathy requires us to depart from such a narrow conception of welfare. One acts from sympathy when one's own welfare is affected by how others are doing - for example, when helping others makes one feel better. As such, sympathy can fairly easily be accommodated in rational choice theory. Commitment, by contrast, refers to a kind of behavior which is motivationally unrelated to the agent's welfare, however broadly defined. One acts from commitment, for example, when one feels compelled to intervene in a certain matter, even if doing so leaves one worse-off. Committed action, according to Sen, cannot be integrated into the standard account of rational choice. In his later work, Sen has further elaborated and indeed radicalized his diagnosis. The possibility of commitment, according to Sen (1985), not only breaks the standard model's link between choice and welfare, it also requires us to depart from the much more general assumption that a person's choices reflect his or her own goals.

Because commitments play an important role in human behavior, Sen's critique challenges the explanatory power of rational choice theory. Moreover, it raises a question about the nature of rationality itself. The "rational fool" of Sen's essay is rational only in the skewed notion of economic theory; in the eyes of those who take a more adequate view of 
rationality, it is plain that he is no more than a simple fool. Three consecutive steps can thus be identified in Sen's critique: (i) render plausible the importance of commitments in human behavior; (ii) demonstrate that rational choice theory - at least in the interpretation favored by most economists - cannot accommodate committed action, and (iii) argue for the need to develop a theory of rationality in action that is not marked by this flaw.

How to account for the rationality of committed action is still very much an open question. To explore this issue, we organized a workshop at the University of St. Gallen in May 2004. ${ }^{1}$ The papers gathered in this Symposium were written for this occasion. The Symposium opens with Amartya Sen's keynote address to the workshop. Sen's paper provides, first, a brief summary of his critique of rational choice theory. Its main emphasis, however, is on arguing for the importance of accommodating commitment in a theory of rational action.

The next two papers are by Philip Pettit and Dan Hausman. Both authors sympathize with the general thrust of Sen's writings on rational choice theory. In particular, they accept the first step of Sen's critique, emphasizing that commitment is an important category of human action that economists have unduly tended to neglect. They do not, however, endorse the second step of Sen's argument. According to Philip Pettit, there is a fundamental flaw in the standard interpretation of rational choice theory, which he sees at work even in Sen's critique. He argues that an alternative interpretation of rational choice theory - one that distinguishes between what he calls "phenomenal" and "non-phenomenal" desires can accommodate committed action.

Dan Hausman, too, defends rational choice theory against Sen's critique. He argues, first, that we should be prescriptive about the notion of preferences. Preferences should specifically be interpreted as "allthings-considered rankings." We can then introduce a clear distinction between the preferences themselves and the factors that influence their development. Commitment, in Hausman's view, is one of these factors. Our "all-things-considered rankings" will depend, among other things, on our commitments. For Hausman, commitments can thus be incorporated in rational choice theory, which is to say that he rejects the second step of Sen's critique.

Unlike Pettit and Hausman, Hans Bernhard Schmid, in this final paper of the Symposium, accepts all three steps of Sen's critique. $\mathrm{He}$ is particularly concerned with the third step, that is, with the

${ }^{1}$ We coorganized the workshop together with Dieter Thomä. The organizers wish to express their gratitude to the Swiss National Research Foundation, The International Students' Committee Foundation and the Research Foundation of the University of St. Gallen for their generous support of this workshop. 
question of how commitment can be incorporated in an alternative theory of rational action. Schmid follows up on an argument put forward by Elizabeth Anderson in an earlier symposium on Sen's work in this journal, which links the rationality of committed action to the structure of collective intentions and actions (Anderson 2001). He examines Sen's claim - strongly objected to by Pettit in his paper - that in committed action, agents do not base their choices on their own goals. According to Schmid, this claim makes perfect sense with regard to collective goals. He argues that Sen's critique could pave the way towards a more adequate (and less individualistic) theory of social action.

\section{REFERENCES}

Anderson, E. 2001. Unstrapping the straightjacket of preferences. Economics and Philosophy 17: 21-38

Sen, Amartya. 1977. Rational fools: a critique of the behavioural foundations of economic theory. Philosophy and Public Affairs 6: 317-44

Sen, Amartya. [1985] 2002. Goals, commitment, and identity. In Amartya Sen, Rationality and freedom. Harvard University Press: 206-24 